\title{
Learning Design Based on 7E Model of Constructivist Approach on Acid Base and Indicators in Physical Science Discipline
}

\author{
Samaresh Adak and Kausik Chatterjee
}

\section{ABSTRACT}

The main purpose of this study is to develop some activity plans by $7 \mathrm{E}$ model of the constructivist approach on the subjects of acid, base and indicators in physical science course. Constructivist $7 \mathrm{E}$ approach consists of seven stage such as Elicit, Engage, Explore, Explain, Elaborate and Extend. Many activities related to physical Science subjects about 'Acid, Base and Indicators' were adapted by each and every stage of constructivist 7E approach. The activity plans were arranged for acquisition knowledge of physical science course. So, the application duration of the activities was determined by these acquisitions. A learning design by $7 \mathrm{E}$ model of constructivist approach of acid base and indicators in physical science course using mind mapping techniques.

Keywords: 7E model, Cognitive reflections, Constructivist approach, Physical Science, Science activity.

Published Online: June 19, 2021

ISSN: $2736-4534$

DOI : $10.24018 /$ ejedu.2021.2.3.103

Samaresh Adak*

Gopal Chandra Memorial College of Education, Kolkata, West Bengal, India. Research Scholar under WBUTTEPA.

(e-mail: adak.chem@ ${ }^{@}$ gmail.com) Kaushik Chatterjee

Satyapria Roy College of Education, Kolkata, West Bengal, India.

(e-mail: chatterjeekausik@ymail.com)

*Corresponding Author

\section{INTRODUCTION}

We are now in the era of scientific evolution where world is guided by science and technology. Society is being revolutionized through the exponential expanding of scientific knowledge. Scientific revolution can be seen every aspect of our lives from discoveries of atomic sciences, to discovery of new vaccines in modern sciences with the help of technological advancements in the field of communication. Science has touched every aspects of human touched, which is actually back bone of human existence. According to NCERT (2006) the inquiring human mind or imaginative human sense responded so many ways by observing the physical and biological world closely. Science is not only confined to just absorbing the evidence, but it is something far to go beyond than this. Today's science education scenario should aim at analyzing the nature of science. Reflecting the nature of science is also obligate ingredients for feeling of a human being.

\section{Constructivism}

According to NCF (2005) recommendation working group of NCERT (2008) apparently highlighted the significance of Constructivist strategy as a teaching approach for reflecting the nature of scientific phenomenon. Constructivism: The New Paradigm from Theory to Practice [1]. In science education constructivism is used as a greater pedagogical approach. Actually, constructivism brings about paradigm shift from teaching to learning, emphasizes on knowledge construction rather than knowledge received. Constructivist 7E-strategy surely act as a catalyst for the learners to analyze the nature of science and also, they can be able to construct their own knowledge that acts as strong background for learning new knowledge with the help of experimentation and reflecting on those previous experiences. The constructivist $7 \mathrm{E}$ learning environment is considered emergent in the classroom [2]. Constructivist 7E strategy also helps to science educators to enhance student's engagement in the real classroom.

\section{METHOD}

This is a descriptive study covering the learning Design and mind map example on the unit of acid base indicators with technologically supported mind mapping technique based on the 7E model of the constructivist approach.

9th grade students have prepared the mind map on acid base and indicators by using mind manager program.

In this study, the activities of the selected topic 'Acid, base and indicator' were adapted by each stage in $7 \mathrm{E}$ model of constructivist approach. The learning design was arranged by objectives determined for Acid, Base, and Indicator course. Actually, the processes related to activities toward the subjects of the unit were not explained in each stage of 7E model.

Total subunit has divided into three parts sections. The first part contains concepts and example of acids. The first part contains concepts and examples of acids. The second part contains concepts and examples of bases. The third part contains concepts of indicator with different examples. The real-life activity based evidences and examples were reflected through the study.

In their course, they have learned that uses of acids in real 
life situation. The teacher asks students to prepare a mind map in their homes to check students' prior knowledge about acid, base, and indicators. When he enters the class, the teacher helps students their mind maps in their group and asks them to prepare a mind map for their group.

The teacher helps them to remember the acid and bases properties and then they start their course activities.

\section{ENGLISH LEARNING DESIGN BY 7E APPROACH}

Name of the School: Delhi Public school, Kolkata UnitAcid, Base and Indicator.

Sub unit:

(a) Acid and base related reactions.

(b) Different types of Indicators.

Teacher (Researcher): Samaresh Adak.

Class-IX

Subject: Physical Science.

\section{A. Brief Summary of Concepts}

Acids: Compounds which contain one or more hydrogen atom and when dissolved in water, they produce hydronium ions $\left(\mathrm{H}_{3} \mathrm{O}^{+}\right)$as the only positively charged ions in that solution.

Examples: Hydrochloric Acid $(\mathrm{HCl})$, Sulfuric Acid $\left(\mathrm{H}_{2} \mathrm{SO}_{4}\right)$ etc.

$$
\begin{gathered}
\mathrm{HCl}=\mathrm{H}^{+}+\mathrm{Cl}^{-}, \mathrm{H}_{2} \mathrm{SO}_{4}=2 \mathrm{H}^{+}+\mathrm{SO}_{4}{ }^{2-} \\
\mathrm{CH}_{3} \mathrm{COOH}=\mathrm{CH}_{3} \mathrm{COO}^{-}+\mathrm{H}^{+}
\end{gathered}
$$

According to Arrhenius in aqueous solution acid molecules ionizes to produce $\mathrm{H}^{+}$ions.

Bases: A base is either a metallic oxide or a metallic hydroxide or aqueous ammonia which reacts with hydrogen ions of an acid to form salt and water only.

For Example $\mathrm{CuO}$ (metallic oxide), $\mathrm{Mg}(\mathrm{OH})_{2}$ metallic hydroxide etc.

\section{B. Learning Goals}

After today's lesson, students will able to:

a. Define what acid is. (Understanding)

b. Analyze why baking powder is used in fire extinguisher? (Analyzing)

c. Establish what the farmer uses to make the land productive. (Applying)

d. Explain the function of antacid. (Applying)

e. Justify with logic why Sodium bi-carbonate is a basic salt. Explain how it can be converted to washing soda. (Analyzing)

f. Justify what will happen if a drop of phenolphthalein is added to the aqueous solution of Sodium carbonate. (Evaluating)

g. The $\mathrm{pH}$ of fresh milk is 6 . Justify with logic how the $\mathrm{pH}$ will change when it is converted to curd. (Creating)

$\mathrm{h}$. Is $\mathrm{H}+$ ion present in basic solution? If yes explain with logic why the solution is logic. (Creating)

\section{Previous Knowledge}

The researcher expects that the following previous knowledge is already within the students. As for examples:

(i) Knowledge about sign, symbol, and valency. (ii) They have clear concept about Electron, Proton and Neutron.

(iii) Concepts of mole.

(iv) Concepts of solution.

\section{Teaching Strategy}

Teacher will present today's subunit before the students by following steps.

\section{- Presentation of topic}

All of you have TV in your house. During watching TV some advertisements disturb frequently. Students, have you seen an advertisement where a woman removes the strain of tomato sauce from clothes by using something? Can you say what the advertisement is about?

Student: Detergent.

Teacher: Yes, you are correct. How was she saying?

Student: The advertisement shows that the strain of tomato jelly has been removed by using detergent.

Teacher: So, what you do understand from it?

Student: Probably, there is a reaction between tomato sauce and detergent. For this the strain is vanished.

Teacher: Yes, you are right.

Here the oxalic acid of tomato sauce reacts with the Sodium Potassium salt of fatty acid and produces salt and water. So, the spot has vanished. Have you ever observed this evidence directly?

Student: No Sir, we want to observe it directly.

- Declaration of the topic

All concepts, reactions and useful application of acid, base and indicators will be taught by using constructivist 7E approach.

Today's Topic: Acid, Base and Indicators

- Presentation of the Topic:

\section{1) Elicit}

In this stage prior knowledge of the learner is elicited by questions and scenarios. Teacher asked some open ended questions based on prior knowledge.

The Teacher asked the students, what happens when a pinch of turmeric powder is added to a glass of water containing lemon juice. Can you say what happens when a pinch of turmeric powder is added to a glass of water containing quick lime? These above questions help students to develop reflective thinking ability by using their previous knowledge.

Mind mapping technique can also be used through constructivist 7E approach. This mind mapping technique used for eliciting the present knowledge and evaluating what learnt is.

Activity - 1:

(a) Baking soda can be used as antacid - do you know?

(b) Baking soda also used as soda acid fire extinguisher.

(c) Baking soda also used to make bread and cake soft and spongy.

(d) Dry hydrogen chloride does not turn blue litmus red where as dilute hydrochloric acid does - why?

(e) During summer season, a milk man usually adds a very small amount of baking soda to fresh milk - why?

(f) Ammonia is a base does not contain hydroxyl group why?

(g) Fresh milk $\mathrm{pH}$ 6, how does the $\mathrm{pH}$ will change as it turns to curd? 


\section{2) Engage}

In this stage events are associated with real life experiences coming from daily activities. Concepts and examples of different acids will be explained with elaboration. The concept of bases with examples and acid base reaction producing salt and water -both will be explained by the teacher using blackboard. The teacher asked the student how is the taste of lemon? And also asked how the taste of turmeric water is? After knowing the taste of lime water, the students recognize which one is acid and which one is basic.

Activity

(a) A gas ' $\mathrm{X}$ ' reacts with lime water and form a compound ' $\mathrm{Y}$ ' which is used as bleaching agent in chemical industry. Indentify ' $\mathrm{X}$ ' and ' $\mathrm{Y}$ '.

(b) A farmer treats the soil with quick lime or calcium carbonate. What is the nature of soil? Why does the farmer treat the soil with quick lime?

\section{3) Explore}

In this stage prior knowledge of the learner is elicited by questions and scenarios. Teacher asked some open ended questions based on prior knowledge.

The Teacher asked the students, what happens when a pinch of turmeric powder is added to a glass of water containing lemon juice. Can you say what happens when a pinch of turmeric powder is added to a glass of water containing quick lime? These above questions help students to develop reflective thinking ability by using their previous knowledge.

Mind mapping technique can also be used through constructivist 7E approach. This mind mapping technique used for eliciting the present knowledge and evaluating what learnt is.

Activity - 1:

(a) Baking soda can be used as antacid - do you know?

(b) Baking soda also used as soda acid fire extinguisher.

(c) Baking soda also used to make bread and cake soft and spongy.

(d) Dry hydrogen chloride does not turn blue litmus red whereas dilute hydrochloric acid does - why?

(e) During summer season, a milk man usually adds a very small amount of baking soda to fresh milk - why?

(f) Ammonia is a base does not contain hydroxyl group why?

(g) Fresh milk $\mathrm{pH}$ 6, how does the $\mathrm{pH}$ will change as it turns to curd?

\section{4) Explain}

In this stage the students try to make explanations about their knowledge explorations and finally they are able to explore their reflective thinking.

Teacher: Have you eaten bitter gourd?

Student: Yes sir, it tastes bitter because it is basic in character.

In $17^{\text {th }}$ Century Chemist Robert Boyle first levels substances as acids and bases on the basis of their properties.

Teacher: Do you know the tastes of grapes?

Student: It tastes sour because it is acidic.

Teacher: Yes, it is acidic, and its $\mathrm{pH}$ is 2

5) Elaborate

In this elaboration stage the learners construct new knowledge.

The students will discuss newly constructed knowledge within the group members or group members of another group. After productive discussion they will generalize their discussion.

Activity:

Teacher (researcher): Have you eaten curd, lassi and guava? How do they taste?

Student: These taste sour. These may be acids.

Teacher (researcher): Can you prove these are acids?

Student: When these touch blue litmus it turns into red. That is why these are acidic.

\section{6) Evaluate}

In this stage learners make comparison and discuss their findings with other learners in or outside their groups.

The students are asked to add what they have learned to the mind maps they have prepared at the beginning of the course. Later, the relationship built between the new information and the existing one is tried to be understood, by observing these mind maps; and the information which is deficient is tried to be improved.

In this way, the mind maps that the students prepare by hand are developed individually by reconstructing knowledge by taking one by one group from the divided groups one of which role plays the acid, the other base and the another as base and another one as indicator. The students are asked to role play based on acid's characteristics, base's characteristics, functions and also indicators function it is.

Activity:

(a) What would be the color of red litmus in a solution of sodium carbonate?

(b) What would be the color of red litmus in a solution of sodium bi-carbonate?

(c) Which gas evolved when $\mathrm{NaHCO}_{3}$ reacts with dilute $\mathrm{HCl}$ ?

(e) "Sodium hydrogen carbonate is basic salt", justify the statement. How it is converted to washing soda - explain.

To test their achieving knowledge teacher asked some questions as follows

By using brain storming techniques, the teacher starts debate with questions:

Activity:

(a) Explain why is $\mathrm{HCl}$ is a strong acid and acetic acid an weak acid. How can it be verified?

(b) You have four solutions $\mathrm{A}, \mathrm{B}, \mathrm{C}, \mathrm{D}$. The $\mathrm{pH}$ of the solution A is 6, B is 9, C is 12 and D is 7. (i) Identify the most basic and acidic solutions. (ii) Arrange the above 4 solutions in the increasing order of $\mathrm{H}+$-ion concentration. (iii) State the change in colour of $\mathrm{pH}$ paper on dipping solution $\mathrm{C}$ and $\mathrm{D}$.

\section{7) Extend}

This stage is one in which students adapt their constructed knowledge to another subjects.

Teacher: How do you feel when an ant sting?

Student: Yes sir, it pains too much where it bites.

Teacher: Can you say why?

Student: When acid falls to any part of our body it arouses burning sensation.

Teacher: Very Good. When ant and bee sting then burning sensation occurs due to formic acid present in the sting. At that time base baking soda has been used to remove from the 
burning sensation. There also acid base reaction occurs.

\section{DESIGN FOR EVALUATION}

At the end of the discussion teacher ask some real life example based probing questions to reconstruct their knowledge.

Example:

(a) Card is not kept in copper and brush utensils why?

(b) Mention the nature of toothpastes. How tooth decay related to $\mathrm{pH}$ ? How can it be prevented?

\section{A. Evaluation: (Worksheet)}

Teacher will present a worksheet to the students to evaluate their acquired knowledge about the topic

1) What is Milk of Magnesia which helps in digestion? (Remembering)

2) When Phenolphthein is added to the sodium carbonates solution -Justify the observation? (Evaluating)

3) Do basic solutions also have $\mathrm{H}^{+}$-ion? If yes, then why are they basic? (Creating)

4) pH of a solution is 10; Solution will be acidic, basic or Neutral? (Analyzing)

5) What is the name of reaction between hydronium $\left(\mathrm{H}^{+}\right)$ and hydroxyl $\left(\mathrm{OH}^{-}\right)$ion? (Remembering)

6) Ferrous sulfate added to nitrate solution and then sulfuric acid was added slowly on it an acid ring layer formed, write name and ring formula. (Creating).

7) Fresh milk has a pH of 6. How do you think the pH will changes as it turns into curd? (Creating)

8) What are the names of ions presents in aqueous solution of ammonia? (Remembering)

9) In which types of solution while adding $\mathrm{H}_{2} \mathrm{SO}_{4}$ white precipitate formed? (Analyzing)

10) In which types of solution while adding $\mathrm{H}_{2} \mathrm{SO}_{4}$ white precipitate formed? (Analyzing)

\section{RESULTS \& SUGGESTIONS}

As constructivist approach focused the significance of reflection on background knowledge in learning, it has a mentionable function in every step of $7 \mathrm{E}$ constructivist learning model.

These 7E steps help the teacher understand the education programme and have the students' knowledge, skills, attitudes, scientific thinking [3]. Constructivist Learning Approach in Science Teaching [4]. In this constructivist 7E model the teachers should elicit the background knowledge of the learners by asking questions and give them chance to associate their knowledge reflections with other subjects at the end of the teaching learning process and transfer it to other subjects [5]. So, background knowledge of the learner should take into consideration and research intending to determined such background knowledge should be done [6], [7].

So, background knowledge of the students should be taken into consideration and research intending to determine such background knowledge should be done.

Through this model the teacher expresses the students the grounding knowledge by interactive question answer participation approach and also gives them a chance to be associated with other discipline at the end of the process and transfer it to other subjects.
The teacher must find out the misconceptions, the plan of the teaching process of the discipline by expressing the prior knowledge of the students. The teacher should also clear the misconceptions because misconceptions personally hinder meaningful learning.

For these reasons the teacher should organize the teaching process to strengthen the background knowledge of the students by determining the probable misconceptions of the learners.

In accordance with the finding of the present study it can be concluded that $7 \mathrm{E}$ model can be applied to express the background knowledge of the learners and to evaluate their learning.

\section{REFERENCES}

[1] Mohapatra, J. K., Mahapatra, M., and Parida, B. K. (2015) Constructivism: The New Paradigm from Theory to Practice. Ghaziabad, U.P.: Atlantic Publishers \& Distributors (P) Ltd.

[2] Oh, P.S., \& Yager, R.E. (2004). Development of constructivist science classrooms and changes in student attitudes toward science. Journal of Education, vol 37: pp. 24-35.

[3] Bybee, R.W., Taylor, J.A., Gardner, A., Scotter, P.V. Powell, J.C., Westbrook, A. and Landes, N. (2006). The Bscs 5E Instructional Model: Origin and Effectiveness. A Report Prepared for the office of Science Education National Institutes of Health. http://science.education.nih.gov/houseofreps.nsf/b82d55fa138783c285 2572c9004f5566/4FILE/Appendix\%20D.pdf (Last Connection:2008,7 July).

[4] Demirci, C. (2009) Constructivist Learning Approach in Science Teaching. H.U. Journal of Education, vol 37: pp. 24-35.

[5] Eisencraft, A., Heltzel, C., Johnson, d., Radcliffe, B. (2006). Artist as Chemist. Science Teacher, vol. 73 (8); pp. 33-37 (ERIC Document Reproduction Service No EJ758670).

[6] Jong, (2005). The Effect of a Constructivist Teaching Approach on Student. Eurasian Journal Phys. Chem. Educ, vol.1(1), pp. 45-50.

[7] Gonen, S., Kocakaya, S., and Inan, C. (2006). The Effect of the Computer Assisted Teaching and 7E model of the constructivist Learning methods on the Achievements and attitudes of High School students. The Turkish Online Journal of Educational Technology, vol.5 (4), pp. 11. 